\title{
PANDEMIA, REPRODUCCIÓN Y PROCREACIÓN: MATERIALES CATEGORIALES PARA UN DELINKING EDUCATIVO Y CULTURAL
}

Pandemic, Reproduction, and Procreation: Categorical Materials for an Educational and Cultural Delinking

CHRISTIAN ANDRÉS SOAZO AHUMADA

CENTRO de INVESTIGACIONES ESTÉtICAS LATINOAMERICANAS (CIELA)

UNIVERSIDAD DE CHILE (CHILE)

CHRISTIANSOAZO@YAHOO.ES

ORCID: 0000-0001-9565-221X

Resumen:

En el presente trabajo se ofrece una reflexión categorial en torno a las principales nociones del pensamiento de Franz Hinkelammert y Jorge Veraza. Su atención principal, en el caso de Hinkelammert, remite a las posibilidades reproductivas del sujeto en un contexto narcotizado por la racionalidad instrumental de la ciencia y mercado capitalistas. En el caso de Veraza, refiere al potencial desobramiento revolucionario que las fuerzas productivas procreativas ejercen en su coexistencia irreductible ante la dominancia de las fuerzas productivas técnicas reificadas. A partir de este marco teórico se dialoga a su vez con las pedagogías radicales expuestas por Freire y Giroux, especialmente con las posibilidades articuladoras entre medialidad/usos pedagógicos tecnológicos y alteridad comunitaria. El argumento de fondo de este planteamiento se focaliza en la educación o formación de un delinking o desconexión categorial radical en la que se tome conciencia de la urgencia de analogar educación con sobrevivencia o producción de vida en contextos necropolíticos y pandémicos cada vez más devastadores como en el escenario contemporáneo. 


\section{Palabras clave:}

Reproducción, procreación, delinking, educación, pandemia

\section{Abstract:}

This article offers a categorical reflection on the main notions of the thought of Franz Hinkelammert and Jorge Veraza. His main attention, in the case of Hinkelammert, refers to the reproductive possibilities of the subject in a context intoxicated by the instrumental rationality of capitalist science and market. In the case of Veraza, it refers to the potential revolutionary inoperosity that the procreative productive forces exert in their irreducible coexistence with the dominance of the reified technical productive forces. Based on this theoretical framework, this work proposes a dialogue with the radical pedagogies exposed by Freire and Giroux, especially with the articulating possibilities between mediality/technological pedagogical uses and community otherness. The underlying argument of this approach is focused on the education or formation of a radical categorical delinking in which becomes aware of the urgency of analogizing education with survival or production of life in increasingly devastating necropolitical and pandemic contexts as in the contemporary scenario.

\section{Keywords:}

Reproduction, Procreation, Delinking, Education, Pandemic 


\section{Introducción}

El escenario pandémico contemporáneo incita a reflexionar críticamente sobre los elementos de continuidad y ruptura apreciados a lo largo de la historia humana por lo menos de la civilización modernooccidental. Obviamente la magnitud y la globalización de este fenómeno en la actualidad es un hecho sin par. Sin embargo, a pesar de la incertidumbre anunciada para el futuro, lo cierto es que en el presente se evidencian una serie de signaturas del pasado que la pandemia de covid-19 no hace más que reforzar. Si se concibe al coronavirus como un vector biológico que no solo da cuenta de una distribución pandémica viral, sino que, a su vez, desde la misma estructuración sistémica global, opera como un "virus social" que usa o se replica a partir de la mayor expansión medial/poblacional llevada a cabo en la historia capitalista, se puede llegar a coimplicar la categoría de inmunidad con la de fetichismo. Esta vinculación dispone de un núcleo semántico farmacológico que veremos desarrollado en toda esta presentación (remedio/enfermedad). Este se relaciona con la ambivalencia entre remedio (confinamiento y vacunación para sobrevivir) y enfermedad (no solo la infección biológica propiamente tal, sino la brutal distribución asimétrica tanto de la vida como de la riqueza en contextos generalizados de excepción). Esta brutal asimetría se desnuda en un contexto en el que existen grandes diferencias entre zonas urbanas y rurales, entre clases acomodadas y lugares precarizados, entre hombres y mujeres, entre infantes y jóvenes, entre digitalización previa en el uso de tecnologías de la información y comunicación (TICS), ya sean redes audiovisuales o informáticas, y el completo desconocimiento del uso y beneficio de estas. Por tanto, este escenario heterogéneo permite ir más allá del actual debate ortodoxo entre presencialidad y virtualidad del aula, pues aquella no garantiza que necesariamente sea una experiencia transformadora (emancipadora/liberadora), sino potencialmente puede ser también biopolítica, normativa, instrumental, como la mayoría de los postulados teórico-prácticos salidos de diseños curriculares estandarizados según promedios y parámetros internacionales.

En consonancia con este mirador teórico se reflexionará en estas líneas en torno a los marcos categoriales generales en los que se inscriben y se pueden proyectar los debates principales sobre educación y cultura de los últimos años, con especial acento en escenarios necropolíticos y necroeconómicos extremos como el actual, concediendo que educar implica dirigir, guiar o encaminar, o sea, "sacar fuera" las mejores capacidades y habilidades de cada sujeto/colectivo para abrirse un camino reproductivo en el mundo. Desde esta premisa se plantea una educación del delinking o desconexión radical del marco categorial del fetichismo técnico-instrumental de la racionalidad y epistemología modernas, en torno al cual se configura un centro productivo inédito vinculado al hecho educativo. Este espacio emergente se encuentra cada vez más dialectizado con el alarmante contexto de destrucción ecológica, crisis económica y política globales, agravado a causa de la pandemia de covid-19. Por tanto, se presenta en este trabajo una reflexión en que las imágenes y experiencias desestabilizadoras, intencionadas con el uso de TICS y recursos pedagógicos cada vez más afines a ese propósito, actúan y se resemantizan desde la peculiar experiencia histórica local/global asentada en vivencias intersubjetivas, comunitarias y alterológicas. De aquí que más que poner el foco en un contexto de saturación y alienación totalitaria y apocalíptica de las imágenes, redes audiovisuales y plataformas digitales sociales, como el descrito ya por la industria cultural (Adorno y Horkheimer, 1998), la imagen del mundo (Heidegger, 1984), la sociedad del espectáculo (Debord, 2005), la performabilidad posmoderna (Lyotard, 1987), y actualmente la inteligencia artificial y la cultura del big data, se insta por una nueva resemantización y conciencia práctica de la fronterización del cuerpo (inmunización/fetichización/narcotización/confinamiento) proveniente de los propios espacios familiares, comunitarios, vinculados con la racionalidad reproductiva y con las fuerzas productivas procreativas de la humanidad. En este sentido, el delinking como figura crítica es a la vez la conciencia de desmontaje o destitución de lo dado, en este caso, de la irrestricta dominación de la racionalidad instrumental en el marco epistémico de la civilización moderno-colonial, como a su vez la afirmación o dignificación positiva de lo procreativo/reproductivo en tanto re-creación o re-constitución sensible e inteligible de "lo humano" en su praxis vital. 


\section{Racionalidad reproductiva del sujeto y pharmakon económico- ideológico del mercado}

Siguiendo el pensamiento de Max Weber (2002), Hinkelammert argumenta que existen dos tipos de racionalidades, una formal y otra material. La primera trata sobre la racionalidad medio-fin en su forma puramente instrumental. Su máxima expresión se dispone en el terreno de las ciencias económicas concebidas como ciencias empíricas, especialmente en la esfera del cálculo monetario (Hinkelammert, 1996: 94). La segunda refiere a la racionalidad material, entendida como racionalidad según contenidos, ya sean creencias, valores, cosmogonías o pensamientos filosóficos. El asunto es que para Weber los juicios de hecho, a saber, los propios de la ciencia empírica moderna, deben ser abordados solo por la racionalidad formal o instrumental, dejando excluidos a los juicios de valor/contenido encarnados en la racionalidad material, o vida-muerte, como la nombra Hinkelammert (94).

En el ámbito de la racionalidad instrumental rige el dominio de la eficiencia como fundamento de lo real. Más que lo verdadero, lo justo o lo bello, lo que determina el campo de la acción racional es la eficiencia. En este horizonte de sentido, una "jugada" técnica, en alusión a Lyotard (Hinkelammert, 1996: 146), es buena simplemente cuando funciona mejor y/o cuando gasta menos que otra. Se establece así una crítica a la eficiencia abstracta de la modernidad en general y del mercado capitalista en particular, al develar al eficientismo como un paradigma o marco categorial fundado sobre una idea de ser humano basada en el "cálculo de intereses" (Hinkelammert y Mora, 2014: 16). La argumentación de Hinkelammert remite aquí a comprender que la racionalidad medio-fin o instrumental es lineal, mientras que la otra lógica, a saber, aquella que concierne no solo a los juicios de valor sino fundamentalmente a los juicios de hecho ligados con la vida y la muerte en el planeta, acrecentados en los contextos pandémicos y necropolíticos contemporáneos, es una racionalidad circular vinculada con el circuito natural de la vida humana (Hinkelammert, 2017a: 200).

Existe entre ambas racionalidades una continuidad orgánica basal, imposible de ser escindible o autonomizable si se observa que ninguna acción calculada de racionalidad medio-fin es finalmente racional, si en sus efectos: "elimina al sujeto que sostiene dicha acción" (Hinkelammert, 2017a: 200). Existe aquí un criterio de imposibilidad referido a cualquier elección sistémica medio-fin — por ejemplo, en el mercado - si desemboca en el suicidio o asesinato. ${ }^{1}$ Esta premisa no es una prescripción valorativa o un juicio de valor alusivo a una ética normativa, incluso de pretensión universal. Constituye, más bien: "un criterio sobre cualquier ética. Como tal, es un criterio portador de un universalismo ético" (Hinkelammert, 1996: 167). No es por tanto una norma ni un conjunto de normas, sino: "un criterio sobre normas éticas" (167), pues lo que se busca es enjuiciar universalmente las éticas como normas o conjunto de normas. Se enfatiza entonces que la única alternativa que hay es afirmar la vida, pues esta: "es la posibilidad de tener fines, sin embargo no es un fin" (Hinkelammert, 2017a: 200).

Marx formula el imperativo categórico de echar por tierra todas las relaciones donde el ser humano sea un: "ser humillado, sojuzgado, abandonado y despreciable" (Hinkelammert, 1996: 167). Se trata aquí de un principio que no es únicamente conformado por la racionalidad formal-instrumental, sino por los juicios de hecho referidos a la racionalidad reproductiva: "juicios cuyo criterio de verdad es de vida y muerte" (168). Valores de uso que deciden sobre la vida y la muerte. Solo en referencia a la focalización en torno al valor de uso se comprende el proceso económico desde el ángulo de la vida y la muerte. Desde esta radicalidad en tanto terreno propio de la pedagogía crítica se comprende e interpela hoy más que nunca a que el "asesinato es una forma de suicidio". Nuestra sociedad está en el camino de cometer un "suicidio colectivo", produciendo así: "un abismo al cual ella misma está siendo arrastrada" (Hinkelammert, 1996: 120). Por tanto, si se quiere frenar la incidencia antropogénica en la crisis ecológica

\footnotetext{
${ }^{1}$ Hinkelammert refiere a la sentencia “asesinato es suicidio" tomando como referencia principal la máxima Bantú difundida por el obispo anglicano Desmond Tutu: “yo soy solamente si tú también eres” (2017b: 294).
} 
global, escenario en que se inscriben las frecuentes mutaciones virales y fenómenos pandémicos contemporáneos, se debe reconocer que la lógica irrefrenable y solipsista de la economía política moderna neoclásica y neoliberal — con su afán de excluir del horizonte de comprensión racional a los valores de uso que deciden sobre la vida y la muerte de la comunidad - conlleva a un proceso de destrucción tendencial del ser humano y de la naturaleza. La percepción cada vez más palmaria del creciente daño ecológico, crisis económica y destrucción del tejido social conlleva a un esfuerzo pedagógico orientado en torno a la radicalización de la significación del orden referencial, contexto histórico de producción o principio material (ecológico/económico/cultural) en el que se desenvuelve la vida cotidiana. Bajo este prisma se advierte que el delinking educativo y cultural solo puede acontecer históricamente debido a la acumulación progresiva de destrucción, violencia, abusos y efectos catastróficos. En este punto el nuevo referente pandémico no actúa como un signo (index) posmoderno más (significante vacío y nihilista), sino como una signatura ética o transontológica (condición de posibilidad de todo lo viviente) que posibilita comprender de mejor modo la crisis contemporánea que vive la humanidad, con sus múltiples y asimétricas formas de expresión, ante la penetración cada vez más voraz e interpelante del horizonte histórico global contemporáneo. En este escenario, se debe fortalecer el desarrollo o toma de conciencia del uso de la racionalidad reproductiva, especialmente en la priorización de objetivos de aprendizajes relacionados con la comprensión de la crisis pandémica, como el autocuidado, el cuidado colectivo, el fomento del pensamiento crítico y reflexivo sobre la información y las noticias circulantes, junto con la compresión de las heterogéneas dinámicas sociales en juego, que implican el fortalecimiento de relaciones empáticas, de tolerancia y no discriminación.

Desde el marco categorial de la economía política clásica, se entroniza entonces el mercado como el lugar donde la decisión sobre la vida y la muerte es consecuencia de la demanda y la oferta de la fuerza de trabajo (Hinkelammert, 1996: 87). En este escenario se despliega la acción narcotizante o farmacológica ${ }^{2}$ del mercado, pues si el salario teóricamente puede estar por debajo de la línea de subsistencia se debe simplemente eliminar a los sobrantes, a saber: "el mercado es armónico y regula por sus tendencias sanas el número de seres humanos disponibles" (87). En este plano se instala la dialéctica entre lo sano y lo enfermo, donde paradojalmente la teoría económica neoclásica opta por una sanidad completamente aséptica, en la cual ya no tiene nada que: "decir acerca de los problemas más urgentes de la vida humana hoy" (92). De aquí que se expone un régimen farmacológico terminal al evidenciar cómo: "el desempleo, la pauperización, el subdesarrollo y la destrucción de la naturaleza dejan de ser problemas económicos. La ciencia empírica no se puede expresar sobre estos problemas sin implicar valores" (92). El quid de la cuestión es que toda la metodología weberiana, basada en que ningún juicio de hecho debe asomarse en la esfera de la racionalidad material, aparece como una: "ciencia completamente aséptica y tautológica" (96; las cursivas son mías). Este hecho se evidencia sobre todo cuando Weber esquiva la discusión con Marx imputándole a su argumento la objeción de "juicio de valor". Esta es, según Hinkelammert, una clara estrategia de inmunización que se "cierra" o "deja fuera" de una discusión racional la argumentación categorial de Marx. Esta forma de inmunización se relaciona con el encapsulamiento o tautologización de los juicios de hecho como juicios medio-fín en tanto modo prioritario de fundamentación categorial de la "acción racional" en las ciencias sociales y humanidades (99). ${ }^{3}$

Hinkelammert argumenta que en coexistencia con la inclinación a la tautologización económica se percibe: "al mercado y al mundo de las instituciones como una mediación necesaria para el acceso a los valores de uso" (Hinkelammert, 1996: 185). Se juega aquí la lógica dialéctica entre racionalidad instrumental y racionalidad reproductiva o lo que, de acuerdo con el pensamiento de Hinkelammert, es la correspondencia entre la función de mediación y la realidad de alteridad respectivamente. Para este

\footnotetext{
2 Sobre la noción de pharmakon, véase Derrida (1975), Stiegler (2013), Herlinghaus (2018). Su referencia básica remite a la ambivalencia ontológica insalvable entre cura/remedio/vida y enfermedad/veneno/muerte.

${ }^{3}$ Hinkelammert comenta irónicamente en relación con el paradigma dominante positivista que: “en nuestro newspeech este método de tautologización y autoinmunización se llama "racionalismo crítico"' (1996: 217; las cursivas son mías).
} 
autor toda mediación es necesaria si en última instancia se rearticula con la alteridad vital, comunitaria, existente en el circuito natural de la vida humana o totalidad cosmológica. Por tanto, una cosa es el mercado como mediación necesaria para el intercambio humano de larga data histórica y otra el mercado capitalista como mediación fetichizada alrededor de la subsunción del trabajo humano a la autovalorización del capital. En este contexto no hay cabida para el maniqué́smo abolicionista de la hegemónica racionalidad instrumental moderna, necesitando así imperiosamente: "de acuerdos, de la creación de consensos, de la sabiduría y de la mediación. La solución no puede ser técnica, sino que sería política" (Hinkelammert, 1996: 157). Es en torno a este límite indecible entre mediación y alteridad que dispone de todo su calado ontológico el fenómeno educativo. Es aquí donde se pondera y recalibra, dependiendo de la contextualización local/global situada, la proporción utilizada entre competencias centrales ligadas con habilidades y destrezas técnicas (propias de cada disciplina básica) fundamentales para cierto conocimiento instrumental del mundo y la profundización de una concepción integral y humanista de la educación y la cultura en la que se refuerce finalmente el valor de la alteridad/comunidad, de la racionalidad reproductiva. En consecuencia, los debidos ajustes curriculares y recursos pedagógicos deben aquí situarse según las necesidades de los colectivos, de las intersubjetividades humanas implicadas en los procesos educativos contemporáneos.

El irresoluble quiasmo entre mediación y alteridad se encarna en torno a un ser infinito como el ser humano, con ansias de trascendencia colectiva o social, quien es atravesado por la finitud de su existencia singular. Se vive ahora de ausencias que, sin embargo, están presentes en sus propios límites. Con este recorte entre infinitud y finitud aparece: "la ausencia de otros mundos y, con eso, el deseo. Hasta el deseo trasciende límites" (Hinkelammert, 2017c: 368). En este mismo sentido, mientras la mediación vehiculiza la realización, ejecución y concreción eficiente de una acción humana para la vida, la dimensión alterológica suministra el marco de democracia radical, igualitarismo y universalismo ético, contribuyente de su legitimidad y necesaria posibilidad real de existencia. En este quiasmo indeterminable el fenómeno educativo oscila conforme a las realizaciones histórico-culturales de cada región del planeta.

\section{Fuerzas productivas procreativas y subsunción real del consumo nocivo}

Análogamente a la importancia asignada a las racionalidades instrumental y reproductiva por Hinkelammert para el proceso de producción y reproducción socio-comunitario, Veraza sitúa a la categoría "fuerzas productivas". Estas entidades son el fundamento del vivir humano, siendo de orden genérico-comunicativas, fundantes y creadoras. Asimismo, refieren en su dimensión más universal y vitalista al: "fundamento positivo procesual-circular autofundado y englobante del todo" (Veraza, 2012: 90). En este punto es donde cabe la distinción crucial planteada por Veraza entre fuerzas productivas técnicas y fuerzas productivas procreativas (90). La primera concierne al polo del complejo orgánico del trabajo humano vinculado con la "producción de objetos", mientras que la segunda remite a aquella dimensión de la subjetividad humana relacionada con la "producción de sujetos" o dimensiones humanas inmateriales del trabajo creador o del disfrute y goce.

Si se comprenden las fuerzas productivas sociales como formas orgánicas de organización humana, estas coimplican una interconexión basal con el todo, configurándose mediante: "la combinación de un factor subjetivo y otro objetivo orgánicamente vinculados" (Veraza, 2012: 69). De aquí que una perspectiva productivista o analítica centrada solo en la técnica en sentido "objetivo" es: "acrítica y no sabría valorar lo que observa" (69). De acuerdo con este contexto, Veraza destaca que las fuerzas productivas son: "valores de uso de la vida y es sólo como tales que contienen un telos, una finalidad, un sentido inmanente. Su carácter orgánico significa que son objetivamente teleológicas (adecuadas a fines vitales)" (2012: 70). Son así esencialmente comunitarias, sustentadas en formas 
orgánicas de organización o de cooperación humanas. Deben comprenderse entonces idénticas al: "proceso de trabajo inmediato o unidad orgánica del sujeto y el objeto de trabajo" (Veraza, 2012: 73).

El marco categorial general que determina el sentido común capitalista, antes que ser un modo tecnológico es uno social. Se somete entonces, siguiendo el pensamiento de Marx, a la subsunción formal y real del trabajo bajo el régimen capitalista y con esto al universo global de fetichización de la mercancía, del capital y el mercado mundial. El fetichismo religioso, entendido como mero formalismo instrumental y solo objeto de las fuerzas productivas "técnicas", posibilita resituar teóricamente lo verdaderamente trascendente, según Veraza, como es la producción material de una sociedad. El acto de desenmascaramiento evidencia que las fuerzas productivas nunca son asépticas o neutrales, en consecuencia, formalmente vacías. Por el contrario, se revelan siempre como significativas, llenas de contenido (razón práctico-material), si por esta noción se entiende la esencia humana como riqueza humana; como horizonte transontológico y transhistórico característico de la condición genérica del ser humano, su posibilidad radical de transformar el mundo y transformarse en ese acto, como es el objetivo de una pedagogía comprometida con las condiciones reales de vida de los más vulnerados del planeta. En este sentido, el "ataque" material a las condiciones basales de vida llevado a cabo durante la pandemia de covid-19 ha sido agravado por la tecnificación instrumental neoliberal, donde los sistemas sanitarios y educacionales se han visto completamente sobrepasados por su falta de cobertura y por su masivo abandono al mercado privado. En el caso de la educación, la gran deserción escolar o las gigantes limitaciones de acceso a medios virtuales de comunicación por vastos sectores de la población mundial son el ejemplo más patente de esta condición de vulneración en la que la racionalidad reproductiva se aprecia fuertemente injuriada.

Es solo desde este contexto situado, en el que predomina la "lugarización de la educación" (Orozco et al., 2021), que se puede enfrentar la no-presencialidad en el aula en el contexto de pandemia cuando no se disponen de los medios tecnológicos de acceso a la información y comunicación. En este punto se pueden fortalecer los nuevos vínculos intersubjetivos producidos desde lo común —aunque muchas veces sean en contextos de hacinamiento y pobreza - desde las propias realidades de cada comunidad educativa, especialmente un trabajo desde las mismas familias, comunidades y organizaciones sociales que pueblan los diversos territorios, recuperando como parte del proceso educativo la riqueza de la experiencia cotidiana en tanto fuente de saber y producción social de conocimientos, bajo el prisma de un "pluriversalismo crítico" y una "ecología de saberes" que pueda contraponerse a los paradigmas utilitaristas y homogeneizadores que cada vez verán más un inmenso nicho de negocios y estratificación social en el mundo de la oferta medial-digital educacional.

Es asimismo desde el individualismo consumista e instrumental al modelo económico neoliberal, que la sobreacumulación cualitativa de capital referida a los valores de uso se puede analizar como eje común entre la crisis económica y la crisis ecológica globales. La respuesta para esta problemática según Veraza proviene de una categoría esencial de su obra como es la "subsunción real del consumo bajo el capital" (2011: 174). Esta noción refiere tanto al sometimiento fisiológico como psicológico de la población conforme a que, tras la sobreacumulación cualitativa reflejada en la ley tendencial a la disminución de la tasa de ganancia, las ramas de la producción comienzan a crecer hipertróficamente a partir de la creación de nuevos valores de uso nocivos que, al ser consumidos, cristalizan el proceso de valorización capitalista. La producción sistemática de valores de uso nocivos abarca tanto las esferas materiales como espirituales, organizativas e institucionales. Es el metabolismo entero de la sociedad, en sus campos económico, político, cultural y educacional, el que se ve alterado cuando se pierden los equilibrios basales entre urgencias, necesidades, satisfacciones y expectativas de la comunidad. En torno a la "subsunción real del consumo bajo el capital" giran todas las alteraciones fisiológicas de nuestro organismo, pues en ella: "es el proceso de vida el que queda en su núcleo alterado" (Veraza, 2017: 3). 
El escenario pandémico contemporáneo se caracteriza por el desarrollo explosivo de la subsunción real del consumo, ejerciendo un reacomodo de los sectores productivos ya sean técnicos, a nivel de la extrema digitalización de todos los recursos de la vida cotidiana (dependencia creciente a plataformas virtuales) como procreativos, a nivel de las nuevas formas de vida o subjetividades asociadas al confinamiento y a la telepresencia. Solo así se comprende que Veraza proponga un hiperfetichismo sui generis (o fetichismo altamente desarrollado) denominado "fetichismo cósico". Este no consiste en la mera cosificación de las relaciones sociales, sino en la: "famelización de las personas; y no en la personificación de las relaciones entre cosas — como sucede en el fetichismo de la mercancía - sino en algo más complejo y desarrollado, la erotización de las cosas" (Veraza, 2017: 11; las cursivas son mías).

Hegel descubre en la relación de sometimiento psicoafectiva que la autoconciencia es "una relación polar entre dos autoconciencias" (Veraza, 2011b: 489). Análogamente, Marx descubre esta misma estructura en la relación de valor entre mercancías. Así como la autoposicionalidad (independencia) del amo adquiere realidad a través de la inautoposicionalidad (sujeción) del siervo: "el valor de una mercancía adquiere objetividad al reflejarse en el valor de uso de otra mercancía" (490). Más allá de la dialéctica del dominio y la servidumbre se trasluce la concepción hegeliana del trabajo y, sobre todo, de la autorreproducción del ser humano, pues Hegel entiende que esta se rige por el principio del trabajo que existe bajo la modalidad de un enfrentamiento entre amo y esclavo, cuyo contenido es el trabajo sometido y el goce del fruto de este. Bajo este enfoque se observa el dominio clasista como un todo cuyo núcleo se halla en el sometimiento directo del trabajo. Esta potestad se justifica desde una idea de muerte concebida de modo idealista y tanático. De aquí que el amo se piense como un ser insensible ante las necesidades materiales del esclavo, conllevando a su vez a su autorrepresentación magnificada y supremacista. Se subraya aquí la importancia de considerar al tanatismo como una referencia destructiva, degenerativa o abortiva, cuya imagen prefigurada del amo tiende, por un lado, a exagerar la incidencia otorgada a la amenaza de muerte por medio de la que somete al esclavo, como por otro, a imprimirle a este una creciente depresión conformista. Se inscribe en este acto la muerte como mandato del ser, donde no solo se desarma al esclavo en función del armazón del amo, sino que además se oculta: "al amo en tanto sujeto que asesina" (Veraza, 2011b: 476). Sartre en Crítica de la razón dialéctica (1963) supo advertir que una dinámica como la propuesta por Hegel solo pudo acontecer obnubilando las condiciones materiales de escasez. En la medida en que esta situación fuera superada, el reconocimiento y la reciprocidad entre los seres humanos no tienen por qué ser: "al modo de la relación entre la autoconciencia amo y la autoconciencia esclavo — una lucha a muerte, una reciprocidad negativa - sino que bien podría ser una reciprocidad positiva" (Veraza, 2011b: 472; nota 452; las cursivas son mías). Veraza sitúa un flanco tensionante en la génesis de la dialéctica de la autoconciencia hegeliana, a saber, en la relación madre-hijo/a. En el vínculo entre la madre y su hijo/a recién nacido/a se revela que la constitución de la autoconciencia humana no tiene lugar a través de la lucha a muerte como Hegel establece, sino mediante: "la relación de cariño y cuidados de la madre hacia su hijo" (2011b: 505).

Veraza estima que el soporte institucional en tanto mediación material faculta el desarrollo de las fuerzas productivas técnicas, históricamente constituidas, sin caer en un abolicionismo ingenuo como el propuesto por el anarquismo. Marx en la "historia crítica de la tecnología" expuesta en El Capital argumenta que la tecnología pone al descubierto el comportamiento activo del ser humano con respecto a la naturaleza: "el proceso de producción inmediato de su existencia, y con esto, asimismo, sus relaciones sociales de vida y las representaciones intelectuales que surgen de ellas" (Veraza, 2012: 68). Esta idea es fundamental para el desarrollo del fenómeno educativo en contextos cada vez más adversos como los generados por la pandemia de covid-19. En efecto, la focalización pedagógica debiera estar cada vez más en torno a las fuerzas productivas procreativas vinculadas con la "técnica-sujeto" o con la "producción

\footnotetext{
${ }^{4}$ Veraza sostiene que la teoría de Marx sobre la "subsunción formal y la subsunción real del proceso de trabajo inmediato bajo el capital" se puede considerar a su vez: "como una matizada aproximación a la dialéctica del amo y el esclavo, la clave fundamental para subvertir los errores de la concepción hegeliana del dominio de clase” (2011b: 469).
} 
de sujetos", pues como se advierte en la cita precedente la dimensión más basal de la tecnología ya se desenvuelve desde el mismo comportamiento activo del ser humano o la producción de su propia subjetividad. Desde la producción de las "relaciones sociales de vida" y las "representaciones intelectuales" se puede incidir política y culturalmente con todo el espesor ontológico que amerita el hecho educativo contemporáneo en nuestros días.

Se revela así entonces un doble fundamento unitario constitutivo de las fuerzas productivas, en el que se manifiesta su relación indecible entre mediación y alteridad, entre el soporte material, empírico o cósico del mundo de los objetos cotidianos, por un lado, y el horizonte transontológico genéricocomunitario de las relaciones alterológicas del tipo "yo soy si tú eres", por el otro. Así, la tecnología ocupa el rol del fundamento objetivo de la mediación material y la cooperación humana el fundamento subjetivo de la dimensión alterológica. Esta dimensión se salvaguarda al concebir a las fuerzas productivas como: "fundamento positivo y circular de la afirmación vital" (93). En efecto, aunque toda esta dinámica sea la expresión cabal de una lógica dialéctica, las fuerzas productivas, comúnmente asumidas en su mera dimensión técnica (fuerzas productivas técnicas), existen también como fuerzas productivas de la humanidad que no son técnicas, en el sentido de servir para la transformación directa de objetos con vistas de satisfacer las necesidades humanas en el campo económico. Estas fuerzas productivas de la comunidad conciernen a la transformación directa de los sujetos, a su formación social, ética, política, cultural y educacional; a su procreación (de ahí su nombre) como una forma de producción renovada o regenerativa de la humanidad. Frente al modo de producción productivista, positivista o neoliberal, cuya acumulación irrestricta se consolida en la continua explotación de plusvalor relativo y la consiguiente innovación tecnológica: "las fuerzas productivas procreativas están arrinconadas y tenidas por una nulidad" (Veraza, 2017: 13).

\section{Pedagogías radicales, delinking y horizontes de liberación}

En el campo de las pedagogías y teorías críticas, Giroux (2003b) compendia ejemplarmente la influencia contemporánea de la cultura positivista y la dominancia irrestricta de la racionalidad instrumental. Para este marco categorial la realidad histórica del sujeto humano queda completamente excluida, y con ello, la posibilidad de asignar significados propios, ordenar la experiencia vivida y luchar contra las injusticias del ordenamiento social. El significado, el tiempo y la memoria quedan así despotenciados de su construcción radical de sentido y realidad históricos. El paradigma positivista sitúa en primer plano la idea de objetividad y neutralidad sistémica. Con el afán de predictibilidad cuantitativa, la práctica educativa positivista excluye de su órbita: "el papel de los valores, los sentimientos y los significados subjetivamente definidos" (Giroux, 2003b: 46). Todo criterio normativo, vinculado con la racionalidad material o reproductiva, se desestima como desviación, interferencia o simplemente perturbación de los hechos reales. Los materiales subjetivos del educando no se valoran en las metas curriculares ministeriales, pues se mueven en el plano de los valores, sentimientos o significados personales.

El asunto cardinal según Giroux es que la racionalidad instrumental positivista ha excluido completamente de la interacción dialéctica/dialógica del conocimiento al horizonte histórico-político del poder y la ideología. Este solipsismo epistémico deja como "ausencia presente" o "grito del sujeto" (Hinkelammert, 1996) a la dimensión ético-crítica e histórica presente en el cuestionamiento a la dominación injusta del poder económico neoliberal y su ideología "oficial" expuesta en la cultura de masas contemporánea. La confusión es aquí, según Giroux, entre objetividad y objetivismo. Como se comentó en relación con el pensamiento de Veraza, es la confusión alojada en el seno de su noción de fuerzas productivas, a saber, donde "objetividad" apela a una armónica relación entre fuerzas productivas técnicas y procreativas, y "objetivismo", alude a una fetichización de la incidencia de las fuerzas productivas técnicas (producción de objetos) a costa de las fuerzas productivas procreativas, ligadas con 
los sujetos históricos, de carne y hueso. En consecuencia, el "objetivismo" refiere a una orientación que es de naturaleza atemporal y ahistórica. En ella, el "hecho" se convierte en: "el fundamento de todas las formas de conocimiento, y los valores y la intencionalidad pierden su eficacia política al quedar abstraídos de la noción de significado" (Giroux, 2003b: 47). De esta suerte, el "hecho empírico fundamentalista" traducido en una poderosa forma ideológica silencia e invisibiliza: "la naturaleza ideológica de su propio marco de referencia" (47).

Donde se refuerza el fetichismo del núcleo racionalidad instrumental/fuerzas productivas técnicas es en la consideración de que los problemas educativos son esencialmente de naturaleza tecnocrática. Bajo este prisma se eleva la metodología a la jerarquía de una verdad revelada excluyendo de todo ámbito de acción a "los propósitos morales como asuntos de opiniones individuales" (Giroux, 2003b: 47-48). Se ignora así el valor de la conciencia histórica para el pensamiento crítico como marco general de comprensión de las humanidades, ciencias sociales, artes y prácticas religioso-cultuales. Se rechaza entonces desde una perspectiva crítica la absolutización de los hechos, abogando por la búsqueda de mediaciones que contribuyan a "dar significado": "no sólo a la naturaleza constitutiva de un acto, sino también a la naturaleza y sustancia mismas del discurso teórico" (Giroux, 2003b: 72), esto es, no solo a la realidad objetual-material de un acto humano sino a la misma producción de subjetividad alojada dentro de los marcos categoriales que circunscriben su discurso teórico.

La noción de cultura debe articularse con la idea de marco categorial que se ha expuesto en los apartados previos, en relación con las formas situadas de percibir, comprender y dar orientaciones para la praxis, según los complejos orgánico-intencionales de comportamiento de una sociedad o agrupación humana determinada. Giroux (2004) aboga por una definición de la noción de cultura esencial para situar el hecho pedagógico alrededor de: "la producción y consumo de significados" (2004: 134) inscritos en culturas historizadas, donde su significación es comprendida como: "un sistema de prácticas, una forma de vida" (135). Los "mapas de significado" no se encuentran solo alojados a nivel del discurso o en el campo cognitivo del sujeto individual, sino que son objetivados en los patrones de las organizaciones y relaciones sociales a través de los que el individuo llega a ser un individuo social. Giroux propone que las teorías de las resistencias en educación debiesen corregir la ortodoxia ya sea de un positivismo neoliberal como de un productivismo estaliniano, esto es, de un objetivismo que solo aboga por la automatización de las fuerzas productivas técnico-instrumentales, la denominada infraestructura económica, donde las escuelas son reducidas al mero reflejo o sombra del modo de producción existente. En contraposición a esta deriva, se propone la noción de "autonomía relativa" con el fin de posibilitar los espacios de producción contrahegemónicos de intervención humana o "no-reproductivos" de la lógica dominante del sistema. La noción de resistencia permite ampliar el foco de análisis de la escuela a su marco mayor de inscripción social, político y cultural. Esta se comprende como "espacios sociales" que, más allá de las explicaciones tradicionales del fracaso de las escuelas, apelan por su valoración ética e indignación política. Las categorías centrales que emergen en la problemática de la resistencia son: "la intencionalidad, la conciencia, el significado del sentido común y la naturaleza y valor del comportamiento no discursivo" (Giroux, 2004: 144-45). Las políticas conservadoras en los últimos años han abandonado la inversión social para adoptar otra de contención social, en la que los servicios del Estado: "se vacían y se reducen a sus funciones más represivas: disciplina, control y vigilancia” (Giroux, 2003a: 110). Las escuelas públicas más que concebirse como "espacios sociales", para los conservadores y neoliberales son una amenaza al paradigma de la "elección de escuela", a saber, la elección/preferencia subjetiva fetichista por sobre las necesidades/deseos en el campo de la educación colectiva. El patrón de "elección de escuela" ataca en su centro al discurso de la democracia y la equidad, reduciendo la idea de ciudadanía a una mera transacción privada, donde las responsabilidades cívicas colapsan ante los voraces patrones de consumo mercantil.

En el caso del pensamiento de Paulo Freire (2007) la concienciación del oprimido exhibe el despliegue de las fuerzas productivas procreativas del ser humano, como sujeto necesitado/deseante y por tanto situado basalmente desde el espacio reproductivo de su comunidad de vida. La concienciación 
posibilita la inserción de los seres humanos en el proceso histórico, como sujetos, es decir, en el sentido fuerte expuesto por Hinkelammert como condición de posibilidad de todos los fines realmente humanos. Estas circunstancias por más de que muestren hilos de continuidad con el pasado exponen igualmente, a partir de la fetichización cada vez más extrema de sus soportes mediales, tecnológicos y biotecnológicos, obscenamente evidenciados en el contexto pandémico actual, sus variaciones cada vez más perturbadoras y radicales. Ante este distópico escenario, las posibilidades pedagógicas, en tanto instancias privilegiadas en la producción de fuerzas procreativas desobrantes de la supremacía instrumental en el reino de las fuerzas productivas técnicas u objetuales (cosificadas), se hacen una necesidad imperiosa, una "ausencia presente" en el sentido expuesto por Hinkelammert.

Frente a la penetración referencial cada vez más apremiante, esto es, significativa del contexto histórico, dada la grave crisis global, social y económica evidenciada con la pandemia de covid-19, junto con el desarrollo hipertrófico de los dispositivos y mediaciones tecnológicas en todos los órdenes de la vida humana, se debe interpretar más allá de una clausura de la totalitarización instrumental de la industria cultural o la sociedad del espectáculo del siglo XX. Esto es, a pesar de que el crecimiento explosivo de la digitalización de las relaciones sociales y de su reificación pudiera aparecer como un espacio sin "exterioridad" o sin una "autonomía relativa", se enfatiza en esta propuesta crítica la radicalización del espacio de experiencias local/global como escenario precisamente de exterioridad crítica. En este ámbito se apela por usar pedagógicamente las imágenes y experiencias que ofrecen los medios audiovisuales y redes informáticas (TICS) siempre en concordancia y sinergia con las sensibilidades locales de la comunidad. Solo así se puede apostar por generar un efecto virtuoso en la medida en que se use políticamente el potencial desestabilizador de las imágenes, o lo que se ha designado en esta presentación como delinking educativo y pedagógico. Una resemantización categorial que se concreta cuando las imágenes usadas en los procesos educativos dejan de ser vistas como imágenes cosificadas o "imágenes objetuales" —utilizadas para cumplir con objetivos de aprendizaje estandarizados y planificaciones curriculares ministeriales - para pasar a corporizarse dialécticamente —a través del espacio de experiencias situado de cada comunidad - en instancias de arraigo y activación geocultural constituidas desde el orden de la racionalidad reproductiva y de las fuerzas productivas procreativas.

Es debido al urgente contexto de necesidades que tanto los estudiantes como sus familias están más predispuestos a la toma de conciencia de la encrucijada global en que se encuentra el mundo. Solo una tradición que reclama por el poder desestabilizador de las imágenes —más allá de su dimensión de vehículos normativo-instrumentales e icónico-disciplinarios- como la expuesta por Warburg (2010), Benjamin (2005), Santos (2009), entre otros, puede apelar por nuevas "ontologías del delinking" que conciban otro marco categorial asociado al acto educativo en contextos pandémicos y de crisis ecológica mundial. Este nuevo modo de comprensión no puede implicar solo el despliegue de habilidades y aprendizajes cognitivo-instrumentales, tributarios de los índices de evaluación estandarizada, sino la formación subjetiva del activismo, la politización, el conocimiento, como atributos propios del hecho pedagógico, en pos del autocuidado y de la responsabilidad colectiva de la comunidad. Solo así la aceleración de todos los procesos estructurales a causa de la pandemia permite visibilizar que ya no se necesitan solo reformas educativas, siguiendo la tradicional linealidad instrumental del conocimiento positivista, sino una verdadera transformación vinculada con el giro en la dominancia (delinking) desde el polo de la fetichización de la racionalidad instrumental/fuerzas productivas técnicas hacia el polo de la racionalidad reproductiva/fuerzas productivas procreativas.

El planteamiento teórico de Freire se sitúa entonces en completa consonancia con el de Hinkelammert, Veraza y Giroux. Precisamente, ubica su teorización sobre la sectarización y la radicalización en torno a la dialéctica encrucijada entre racionalidad instrumental/fuerzas productivas técnicas/mediación institucional y racionalidad reproductiva/fuerzas productivas procreativas/alteridad comunitaria. La sectarización remitiría así a la fetichización de la racionalidad instrumental/fuerzas productivas técnicas y la radicalización al enraizamiento crítico en torno a la transformación liberadora 
de la realidad concreta y objetiva asociada a la reproducción-procreación comunitaria. Freire se ubica en este núcleo conceptual muy próximo a la idea de "irracionalidad de lo racionalizado" de Hinkelammert, al sostener que: "la sectarización en tanto mítica es irracional y transforma la realidad en algo falso que, así, no puede ser transformada" (2007: 20). Como irracionalidad mítica se fetichiza como apariencia o ficción. Así, el sujeto sectario: "no percibe, no puede percibir o percibe erradamente, en su “irracionalidad" cegadora, la dinámica de la realidad" (20).

Freire reflexiona sobre la dialéctica entre opresión/liberación y deshumanización/humanización situándose en el espacio de experiencias históricas de los oprimidos. Desde este lugar de enunciación se procura el anhelo de humanización a través de la recuperación de la humanidad perdida por parte de estos. Esta recuperación solo puede ser un acto de creación o de recreación, en la medida en que se ponen en juego las fuerzas productivas procreativas más genuinas del ser humano, siempre dialectizadas con la anticipación real y concreta de un orden material más justo del mundo. ${ }^{5}$ No se puede aspirar a llevar a cabo solo un "cambio de roles", es decir, donde el oprimido pasa a ser, reproduciendo mecánicamente la inercia colonial-capitalista de las fuerzas productivas técnico-instrumentales, un "nuevo opresor del antiguo opresor", sino ejecutar realmente la condición de: "restauradores de la humanidad de ambos" (Freire, 2007: 25; las cursivas son mías). Es decir, más que un "cambio de roles" se agencia una transformación general de las reglas del juego, en este caso, de las relaciones de dominación. Más que ejercerse una teoría de la resistencia/emancipación se sientan las bases para una teoría de la re-existencia, delinking o desconexión radical en tanto marco categorial, método y horizonte epistémico. Esta debiera reforzar una sui generis praxis-poiesis que fuera la producción de una acción en sí misma, antifetichista y soberana, anclada primariamente en torno al polo de la producción de intersubjetividad comunitaria.

Si se analiza con más detalle la dinámica interna presente en la reflexión de Freire, se advierte que, cuando el oprimido descubre que "aloja" o "contiene" en su interior al opresor a partir de una larga tradición de educación bancaria, es cuando se pueden efectuar realmente la pedagogía y praxis liberadoras. Se vive antes de esta instancia una dualidad en la cual: "ser es parecer y parecer es parecerse con el opresor" (Freire, 2007: 26). Se corporiza en el oprimido, si seguimos a Veraza, precisamente esa "dualidad unitaria" - factor subjetivo y objetivo orgánicamente intencionados, asociados con el trabajo y las fuerzas productivas - entre ser y parecer. En torno al "parecer" se identifica con el opresor al inmiscuirse en la mímesis de su cultura opresiva, a través de la reproducción mecánica de las fuerzas productivas técnicas/racionalidad instrumental fetichizada del opresor/colonizador introyectada en el oprimido. En el ámbito del "ser", se busca recuperar o liberar sus propias fuerzas productivas procreativas/racionalidad reproductiva, vinculadas con la emancipación universal de la humanidad y de los valores de uso esenciales que no solo deciden sobre la vida y la muerte de la comunidad, sino que también sueñan con el "buen vivir" o la vida plena de todos.

Sin embargo, Freire no deja de enfatizar que, sin negar el papel de la subjetividad, en este caso más ligada a su acepción "débil" de "elecciones y preferencias subjetivas" en vez de "necesidades y deseos objetivos", la exigencia de radicalidad amerita necesariamente la transformación objetiva de la situación opresora. Es aquí donde ciertamente el uso actual de internet y plataformas mediales busca acercar la escuela, los procesos educativos, a los hogares y comunidades de los estudiantes, caracterizados por brutales asimetrías en relación con situaciones de discapacidad, pobreza, diversidad lingüística, inmigración, comunidades indígenas, violencia patriarcal, entre muchas otras. Es aquí donde se busca sincronizar el delinking educativo y cultural, mediante la sensibilización crítica y reflexiva de los materiales audiovisuales usados en las plataformas mediales, con las realidades peculiares del contexto histórico local, que son precisamente las que padecen los efectos más devastadores de la actual crisis ecológica, económica y política globales.

\footnotetext{
${ }^{5}$ Freire propone aquí una dialéctica entre la denuncia de la situación deshumanizante del presente y el anuncio o anticipación de la esperanza utópica por un mundo mejor realizable desde la praxis material del presente (2012: 102).
} 
La objetividad dicotomizada de la subjetividad en el oprimido es para Freire objetivismo al igual que Giroux. Es decir, la negación de la subjetividad en tanto fuerzas productivas procreativas es la objetualización de las fuerzas productivas meramente técnicas o reificadoras. Por tanto, en concordancia con un pensar dialéctico, acción y mundo se copertenecen en una íntima relación de solidaridad. Aún más, la acción solo es humana cuando: "más que un mero hacer, es un quehacer, vale decir, cuando no se dicotomiza de la reflexión" (Freire, 2007: 34; las cursivas son mías). La acción es realmente humana cuando no es solo un "hacer" en tanto mero "hecho" (objetivismo positivista), sino un "quehacer" que, siendo un hecho dialectizado, se encuentra totalmente subsumido con los valores, memoria histórica, a saber, los contenidos materiales de la racionalidad reproductiva y de las fuerzas productivas procreativas vinculadas con la cultura y la educación en su sentido simbólico-material más profundo.

\section{Conclusiones}

En el contexto global contemporáneo el eufemismo de "cambio climático" quedó ya atrás según el último informe del Grupo Intergubernamental de Expertos sobre Cambio Climático (IPCC) de las Naciones Unidas, pues ante lo que se encuentra actualmente la humanidad es frente a una "crisis climática" de consecuencias devastadoras. Según este escenario, más que un efecto iatrogénico civilizatorio lo que se aprecia son las irreversibles manifestaciones del Antropoceno, o sea, el impacto global de las actividades humanas sobre los ecosistemas terrestres. Según este panorama, la intensa presión sobre los ciclos biológicos ha derivado en escenarios pandémicos mucho más recurrentes en las últimas décadas. Sin embargo, lo que no se subraya con el mismo ahínco es la fase terminal del sistema mundo capitalista que autores como Wallerstein (2010) han desarrollado minuciosamente, para exponer cómo en los momentos de crisis terminal de un sistema se da una importancia crucial a la praxis (poiesis) de los sujetos colectivos. En este escenario se instala a su vez la Agenda 2030 de la Organización de Naciones Unidas con sus objetivos de desarrollo sostenible (ODS), ${ }^{6}$ apelando por un currículo integral y humanista que considere una educación inclusiva y equitativa como un factor crucial para mejorar los niveles de bienestar, prosperidad y sostenibilidad ambiental de la población mundial.

De aquí que se insista en reforzar el horizonte macropolítico en el que binariamente las posibilidades de realización humanas se mueven en el terreno de la vida y la muerte (norte y sur globales), de la liberación y la opresión. Este es el horizonte donde predomina el fetichismo de la racionalidad instrumental reflejado en el paradigma de la ciencia y la economía política modernas. Es a su vez el espacio por antonomasia en el que se puede trabajar por las fuerzas procreativas del sujeto inscritas en su racionalidad reproductiva. Aquí la formación educacional materializa una sui generis forma de "trabajo" (complejo orgánico subjetivo/objetivo) en estrecha simbiosis con la transformación social y cultural. Es desde aquí, entonces, desde donde se exhorta por un delinking o desconexión categorial radical que desemboque en una verdadera "toma de conciencia", donde todo hecho educativo sea, en su más hondo sentido hermenéutico, una instancia de aprendizaje/práctica de sobrevivencia, y por extensión, de buena vida o "buen vivir". Sin embargo, desde este punto de vista no se prescinde del horizonte micropolítico en el que se desarrollan múltiples manifestaciones concretas, cotidianas, donde se disputa finalmente la hegemonía formal de los medios/mediaciones, a saber, nuevas formas de interacción virtuales, aceleración de los procesos digitales, borramiento entre lo público y lo privado, entre muchas otras. Estos dos horizontes no son contrapuestos, sino que se encuentran completamente dialectizados. El énfasis de esta propuesta releva como una necesidad ineludible, ante la exigencia contextual cada vez más demandante, el reforzamiento de la educación de ese "espacio de delinking" comprendido como

\footnotetext{
${ }^{6}$ Véase el informe de covid-19 de la Cepal-Unesco (2021), La educación en tiempos de la pandemia de Covid-19. Consultado el <https://www.cepal.org/es/publicaciones/45904-la-educacion-tiempos-la-pandemia-covid-19> (12/10/2021).
} 
desprendimiento o desmontaje no solo teórico o discursivo, sino también técnico-instrumental (objetivomaterial) a partir de una transformación radical reproductivo-procreativa (subjetivo-inmaterial).

En consecuencia, la interpelación aquí sugerida no desestima la "autonomía relativa" propuesta por Giroux, en relación con el uso de las mediaciones materiales o históricas concretas. Pero a su vez tampoco se confía en que en ese campo objetual se pueda "desobrar" o reproducir contrahegemónicamente el reparto brutalmente asimétrico de mediaciones fetichizadas a lo largo de la historia. Se incita aquí no solo a desobrar formalmente desde las técnicas y mecanismos tecnológicos, sino igualmente a "hiperobrar" procreativamente alrededor del fundamento positivo, el marco general u horizonte de comprensión que pone al sujeto viviente como centro productivo, ya sea a través del uso de plataformas mediales o del despliegue de incentivos para su educación familiar y comunitaria. Esta práctica formativa ya no es una opción sino una necesidad, a saber, la más urgente y la más noble que interpela a la humanidad en estos días, asociada con fomentar relaciones sociales y naturales cooperativas, sentimientos de solidaridad y colaboración en torno al bien común o al cuidado del otro (lo reproductivo/procreativo). Comprensión vivencial de la incierta realidad pandémica que llegó para quedarse, sobre la base de relaciones comunitarias y de cohesión sociales, donde el sentido arquetípico de todo acto pedagógico es sostener la dignidad humana y la vida material de todo el planeta.

\section{Bibliografía}

BENJAMIN, Walter (2005), Tesis sobre la historia y otros fragmentos. Echeverría, Bolívar (trad.). Ciudad de México, Contrahistorias.

Debord, Guy (2005), La sociedad del espectáculo. Pardo, José Luis (trad.). Valencia, Pre-textos.

DERrIDA, Jacques (1997), “La farmacia de Platón”, en La diseminación. Arancibia, José Martín (trad.). Madrid, Editorial Fundamentos, pp. 93-261.

FreIre, Paulo (2007), Pedagogía del oprimido. Ciudad de México, Siglo XXI ediciones.

FreIRE, Paulo (2012), Pedagogía de la indignación. Cartas pedagógicas en un mundo revuelto. Buenos Aires, Siglo XXI editores.

GIROux, Henry (2003a), La inocencia robada. Juventud, multinacionales y politica cultural. Manzano, Pablo (trad.). Madrid, Ediciones Morata.

Giroux, Henry (2003b), Pedagogía y política de la esperanza. Teoría, cultura y enseñanza. Pons, Horacio (trad.). Buenos Aires, Amorrortu.

GIROuX, Henry (2004), Teoría y resistencia en educación. Una pedagogía para la oposición. Méndez, Ada (trad.). Ciudad de México, Siglo XXI editores.

Heidegger, Martín (1984), Caminos de bosque. Cortés, Helena y Arturo Leyte (trad.). Madrid, Alianza Editorial

Herlinghaus, Hermann (2018), The Pharmakon. Concept Figure, Image of Transgression, Poetic Practice. Heidelberg, Universitätsverlag Winter.

HinKeLAMmeRT, Franz (1978), Las armas ideológicas de la muerte. Salamanca, Ediciones Sígueme.

HinkELAMMERT, Franz (1987), Democracia y Totalitarismo. San José-Costa Rica, DEI.

HinkELAMMERT, Franz (1996), El mapa del emperador. Determinismo, caos, sujeto. San José de Costa Rica, DEI.

HinkelammerT, Franz (2008), “Sobre la reconstitución del pensamiento crítico”, en Revista Polis, vol. 7, n. ${ }^{\circ}$ 21, pp. 367-395. DOI: <http://dx.doi.org/10.4067/S0718-65682008000200017>. 
HiNKELAMMERT, Franz (2017a), "La irracionalidad de lo racionalizado: comentarios metodológicos sobre la razón instrumental y su totalización”, en Antología esencial sobre Franz. Hinkelammert. La vida o El capital. El grito del sujeto vivo y corporal frente a la ley del mercado. Buenos Aires, CLACSO/ALAS, pp. 189-226.

HiNKELAMMERT, Franz (2017b), "El sujeto, el anti-sujeto y el retorno del sujeto (Interculturalidad y fundamentalismo)", en Antología esencial sobre Franz. Hinkelammert. La vida o El capital. El grito del sujeto vivo y corporal frente a la ley del mercado. Buenos Aires, CLACSO/ALAS, pp. 293-318.

HinKeLAMMERT, Franz (2017c), "La reflexión trascendental. Preludio para una antropología”, en Antología esencial sobre Franz Hinkelammert. La vida o El capital. El grito del sujeto vivo y corporal frente a la ley del mercado. Buenos Aires, CLACSO/ALAS, pp. 361-375.

HinKelammerT, Franz y Henry MORA (2014), Hacia una economía para la vida. La Habana, Editorial Caminos.

HorkHEIMER, Max y Theodor Adorno (1998), Dialéctica de la ilustración. Sánchez, Juan José (trad.). Madrid, Editorial Trotta. Traductor.

LYOTARD, Jean-Francois (1987), La condición Postmoderna. Informe sobre el saber. Antolín Rato, Mariano (trad.). Madrid, Ediciones Cátedra.

OrOzCO, Rosangela; RENNA, Henry y Lenin ROMERO (comps.) (2021), Educación lugarizada desde lo común: una alternativa del Sur en pandemia. Buenos Aires, Muchos Mundos Ediciones; Consejo Latinoamericano de Ciencias Sociales (CLACSO), Consejo de Educación Popular de América Latina y el Caribe (CEAAL).

SANTOS, Boaventura de Sousa (2009), Una epistemología del sur. Buenos Aires, Clacso-Siglo veintiuno editores.

SARTRE, Jean-Paul (1963), Crítica de la razón dialéctica. Lamana, Manuel (trad.). Buenos Aires, Editorial Losada.

STIEGLER, Bernard (2013), "Escritura y Fármacon" (entrevista a Bernard Stiegler), Escritura e imagen, vol. 9, pp. 325-337.

VERAZA, Jorge (2010), "Crisis económica y crisis de la forma neoliberal de civilización (o de la subordinación real del consumo bajo el capital específicamente neoliberal)", Argumentos, vol. 23, n.o 63, mayo-agosto, pp. 123-157.

VERAZA, Jorge (2011a), "La subordinación real del consumo bajo el capital y los límites objetivos del capitalismo", en Del reencuentro de Marx con América Latina en la época de la degradación civilizatoria mundial. La Paz, Vicepresidencia del Estado Plurinacional de Bolivia.

VERAZA, Jorge (2011b), "Hegel y Freud en la historia del capitalismo y la reconstrucción del marxismo en el siglo XXI", en Del reencuentro de Marx con América Latina en la época de la degradación civilizatoria mundial. La Paz, Vicepresidencia del Estado Plurinacional de Bolivia, pp. 463-516.

VERAZA, Jorge (2012), Karl Marx y la técnica desde la perspectiva de la vida. Ciudad de México, Editorial Itaca.

VERAZA, Jorge (2017), "El sentido común mercantil capitalista y sus fetichismos (a 150 años de la publicación del tomo I de El capital)", en Teoría y Crítica de la Psicología, n. ${ }^{\circ}$ 9, pp. 1-15.

WALLERSTEIN, Immanuel (2010), Utopística o las opciones históricas del siglo XXI. Ciudad de México, Siglo veintiuno editores.

Warburg, Aby (2010), Atlas Mnemosyne. Chamorro Mielke, Joaquín (trad.). Madrid, Akal.

WEBER, Max (2002), Economía y sociedad. Medina Echavarría, José; Roura Farella, Juan; Ímaz, Eugenio; García Máynez, Eduardo y José Ferrater Mora (trads.). Ciudad de México, Fondo de Cultura Económica. 